\title{
Discussion of causes and consequences of sleepiness among college students, 2014
}

\section{Brad Wolgast}

Center for Counseling and Student Development, University of Delaware, Newark, DE, USA
Correspondence: Brad Wolgast

University of Delaware,

Newark, 26I Perkins Student Center, DE 19716, USA

Emailbradw@udel.edu
This article was published in the following Dove Press journal:

Nature and Science of Sleep

19 May 2016

Number of times this article has been viewed

\section{Dear editor}

I was recently directed to, "Causes and consequences of sleepiness among college students", from Hershner and Chervin. ${ }^{1}$ As a psychologist who specializes in treating college student sleep problems, I was very pleased to see this article. Overall, it is a gem: thorough, well-conceived, and thoughtful. However, I have concerns about two sections.

First, on page 74, Hershner and Chervin ${ }^{1}$ write, "How much sleep a young adult needs is not clearly known, but is thought to be 8 hours." They then cite Wehr et al ${ }^{2}$ as well as Van Dongen et al. ${ }^{3}$ These choices are surprising as reference for the assertion that young adults need approximately 8 hours of sleep.

The Wehr et al article makes no such assertion. No mention of demographics is given whatsoever of the 15 subjects included in their study, so it is surprising to make an assertion about sleep need for any particular age group based on their work.

Van Dongen et al ${ }^{3}$ seems to come closer. While the authors do not assert an 8-hour sleep need, they use 8 hours as a baseline for sleep for their subjects. However, this group of 48 subjects are aged 21-38, and no further information is given about their demographics. While it is possible that the average age of participants could be vaguely similar to college-aged students, it is a stretch to assume that this population represents college-aged students without more information.

There is a great deal of research regarding young adults, late adolescents, and sleep need. I expected references to Mary Carskadon's work, ${ }^{4,5}$ to the 2010 Wolfson article ${ }^{6}$ looking at emerging adults' sleep, as well as Galambos et al $^{7}$ focusing on the four university years and how students in different years sleep. Research with adolescents has shown a sleep need of $91 / 4$ hours, and most college students are nearer to adolescence than they are to adulthood. ${ }^{4,5}$ While it is true there is no clear agreed-upon sleep need for college students, it seems important to reference those who are doing important work in the area of sleep need.

My second concern is on page 76 . Hershner and Chervin ${ }^{1}$ include a brief, much needed section about caffeine and energy drinks. I believe there are two flaws in this section. The first one is the attention to energy drinks. While somewhat varied in caffeine amounts, energy drinks are actually much more consistently caffeinated than coffee. While a handful of energy drinks break the rule, most of them are caffeinated at the rate of $10 \mathrm{mg} /$ fluid ounce. Coffee, on the other hand has no limitations placed on it. While the US Food and Drug Administration tries to keep a control on energy 
drinks and energy shots (10 mg/fluid ounce, and $100 \mathrm{mg} /$ fluid ounce, respectively), there are no limits on the caffeine in coffee. In my opinion, the argument against energy drinks is not as important as an argument against the very common, very strong coffee that is now sold everywhere.

This leads to the second difficulty with the caffeine section. Hershner and Chervin ${ }^{1}$ refer to the Walsh et al article ${ }^{8}$ and cite their finding that, "caffeine, equivalent to 2-4 cups of coffee taken at night can increase sleep latency on average from 6.3 to 12.1 minutes [...]". Looking at the Walsh article, each of their experiments includes participants drinking $300 \mathrm{~mL}$ (about 10 ounces) coffee with $4 \mathrm{mg}$ of caffeine per kilogram of body weight. To put this in American college student terms, a 120 pound person would be drinking $217 \mathrm{mg}$ of caffeine; a 180 pound person would be drinking $326 \mathrm{mg}$ of caffeine in that experiment. Walsh et al were presumably giving participants a dose equivalent to 2-4 cups of coffee as it was brewed in 1990, in one 10 ounce cup.

Because coffee was brewed with less caffeine at the time of Walsh et al's article ${ }^{8} 200-320 \mathrm{mg}$ of caffeine was consistent with 2-4 cups of regular coffee. It was commonly described at that time that a standard cup of coffee was 8 ounces and would have about $80-100 \mathrm{mg}$ of caffeine (10 mg/ounce).

Due to changes in the coffee market, caffeine in coffee has changed since 1990. The prevalence of coffee brewed very strongly has never been as it is today. In addition, the size of the average "cup" of coffee has nearly doubled since 1990; it certainly is not eight ounces anymore. At most coffee stores it is difficult to find an 8-ounce cup of coffee. Among the college students I meet with, the most common sized coffee purchase seems to be 16 ounces or larger.

The issue here is that 1990 coffee is not the same as 2016 coffee in size or strength. When Hershner and Chervin ${ }^{1}$ write that "caffeine, equivalent to 2-4 cups of coffee taken at night can increase sleep latency on average from 6.3 to 12.1 minutes", they miss the point that cups of coffee today are not what they were 25 years ago. A more clear way of saying this is that 200-300 mg of caffeine can increase sleep latency, which is about equivalent to 12-16 ounces of today's premium coffee (Table 1).

I greatly appreciate Hershner and Chervin's ${ }^{1}$ article. I believe it provides a thorough and thoughtful review of a tremendous amount of information related to college students
Table I Amount of caffeine in popular commercial coffee

\begin{tabular}{llll}
\hline Coffee size & $\begin{array}{l}\text { Caffeine } \\
\text { amount per } \\
\text { drink }\end{array}$ & $\begin{array}{l}\text { Total caffeine } \\
\text { for 2-4 “cups" }\end{array}$ & Store \\
\hline 8 ounce & $180 \mathrm{mg}$ & $360-720 \mathrm{mg}$ & Starbucks \\
10 ounce & $215 \mathrm{mg}$ & $430-860 \mathrm{mg}$ & Dunkin Donuts \\
12 ounce & $260 \mathrm{mg}$ & $520-1,040 \mathrm{mg}$ & Starbucks \\
16 ounce & $302 \mathrm{mg}$ & $604-1,208 \mathrm{mg}$ & Dunkin Donuts \\
16 ounce & $330 \mathrm{mg}$ & $660-1,320 \mathrm{mg}$ & Starbucks \\
20 ounce & $415 \mathrm{mg}$ & $830-1,660 \mathrm{mg}$ & Starbucks \\
20 ounce & $431 \mathrm{mg}$ & $862-1,724 \mathrm{mg}$ & Dunkin Donuts \\
\hline
\end{tabular}

Note: Data from www.caffeineinformer.com., ${ }^{910}$

and their sleep. My hope is that in the future, articles that discuss caffeine and caffeinated beverages and products could cite the likely amount of caffeine rather than the number of "cups", and then encourage caffeine users to be curious about how much caffeine is contained in what they are drinking.

\section{Disclosure}

The author reports no conflicts of interest in this communication.

\section{References}

1. Hershner SD, Chervin RD. Causes and consequences of sleepiness among college students. Nat Sci Sleep. 2014;6:73-84.

2. Wehr TA, Moul DE, Barbato G, et al. Conservation of photoperiodresponsive mechanisms in humans. Am J Physiol. 1993;265(4 Pt 2): R846-R857.

3. Van Dongen HP, Maislin G, Mullington JM, Dinges DF. The cumulative cost of additional wakefulness: dose-response effects on neurobehavioral functions and sleep physiology from chronic sleep restriction and total sleep deprivation. Sleep. 2003;26(2):117-126.

4. Wolfson AR, Carskadon MA. Sleep schedules and daytime functioning in adolescents. Child Dev. 1998;69(4):875-887.

5. Carskadon MA, Dement WC. Normal human sleep: an overview. Principles and practice of sleep medicine. 2000;4:13-23.

6. Wolfson AR. Adolescents and emerging adults' sleep patterns: new developments. J Adolesc Health. 2010;46(2):97-99.

7. Galambos NL, Vargas Lascano DI, Howard AL, Maggs JL. Who sleeps best? Longitudinal patterns and covariates of change in sleep quantity, quality, and timing across four university years. Behav Sleep Med. 2013; 11(1):8-22.

8. Walsh JK, Muehlbach MJ, Humm TM, et al. Effect of caffeine on physiological sleep tendency and ability to sustain wakefulness at night. Psychopharmacology (Berl). 1990;101(2):271-273.

9. Dunkin' Donuts coffee caffeine content guide (updated). Caffeineinformer. [webpage on the Internet]. Available from http://www.caffeineinformer. com/complete-guide-to-dunkin-donuts-caffeine-content. Accessed 22 February 2016.

10. The complete guide to Starbucks cafeine. Caffeineinformer. [webpage on the Internet]. Available from http://www.caffeineinformer.com/thecomplete-guide-to-starbucks-caffeine. Accessed 22 February 2016. 


\section{Author's response}

Shelley D Hershner

Department of Neurology, University of Michigan, Ann Arbor, MI, USA

Correspondence: Shelley D Hershner

Department of Neurology, University of Michigan, Med Inn C728, I500

East Medical Center Drive, Ann Arbor, MI, USA

Tel + I 7349366295

Fax + I 7346479065

Email shershnr@umich.edu

\section{Dear editor}

I would like to thank Dr Wolgast for the thoughtful commentary to the paper "Causes and consequences of sleepiness among college students". In this paper we state, "how much sleep a young adult needs is not clearly known, but is thought to be 8 hours". Surprisingly, defining optimal sleep duration can be controversial. ${ }^{1,2}$ Many studies on adolescents and college students describe students' actual sleep patterns and sleep duration, but studies on current behavior have limited ability to define a young adult's sleep requirements..$^{3-7}$ In defining adequate sleep duration, other studies look at the associations between sleep duration and various aspects of health, well-being, and performance. This type of study is primarily looking for detrimental effects on waking behaviors or health parameters. One excellent example of this is the recent consensus statement on the recommended amount of sleep for a healthy adult. ${ }^{8} \mathrm{I}$ am using this particular article as an example of the science that may lead to recommendations about adequate sleep duration, and not to imply that these data are directly applicable to college students. Alternatively, adequate or optimal sleep duration can be evaluated based on sleep extension protocols. Here the focus may be looking at physiologic parameters or potentially optimizing some aspect of health or performance. The Wehr et al article is an example of this methodology. ${ }^{9}$ Although this study was not designed to specifically address adequate sleep duration, it does have some intriguing support for a recommended sleep duration of approximately 8 hours.

In the Wehr et al study, subjects had two experimental conditions; short-day protocol (10 hours light/activity and 14 hours dark/rest) and short night protocol (16 hours light/ activity and 8 hours dark/rest). Subjects completed 1 week of the short night protocol, then after 2 weeks transitioned to 4 weeks of the short day protocol. Four weeks of the short day protocol is an important component because this allowed subjects to "catch up" on any sleep deprivation which occurred during the short night protocol.
At the 4th week of the short day protocol, total sleep duration was 8.21 hours of sleep. The article mentions, "in the long nights, unlike the short nights, subjects spent much time in a state of quiet wakefulness characterized by a prominent and sustained alpha rhythm in the EEG [electroencephalogram] (unpublished observations)". This increased wakefulness suggests that subjects were no longer sleep deprived and consequently have a decrease in sleep efficiency (total sleep time divided by time in bed). ${ }^{10,11} \mathrm{~A}$ high sleep efficiency can be an indicator of sleep deprivation. ${ }^{12}$ This sleep extension protocol showed that after acclimating to 14 hours of time in bed subjects slept for 8.21 hours.

Interestingly, in the 4th week, subjects reported feeling happier and more energetic with a significant decrease in fatigue. The age demographics for this study were adults between 20-36 years of age. Therefore, it is certainly possible that some among this age group are older than traditional college students, however, according to National College Health Assessment, in 2015, 19\% of college students were 25 years of age and older. ${ }^{13}$ In a study with 3 days of sleep extension, among subjects with a mean age of $21.8 \pm 3.7$ years, the average total nocturnal sleep duration was 8.5 hours. ${ }^{10}$ Among males with a mean age of $24.4 \pm 4.4$ years, sleep duration following sleep extension was 8.94 hours. ${ }^{6}$ So although optimal sleep duration for any age can be challenging to define, there is at least some evidence to suggest that it is at least 8 hours. ${ }^{6,9}$

I want to thank Dr Wolgast on his insightful discussion on energy drinks, coffee, and caffeine. It is certainly important to consider how the amount of caffeine and the volume of typically consumed coffee has increased over the years. The rising popularity of combining energy drinks and alcohol is an additional concern, as both alcohol and energy drinks can adversely impact sleep and daytime function. Twenty-four percent of past 30-day drinkers reported drinking alcohol mixed with energy drinks. ${ }^{14}$ The use of energy drinks may increase alcohol consumption and heavy drinking. ${ }^{15}$ Further research, consistent with how students are currently consuming caffeine, is certainly needed to better gauge the impact that caffeine has on sleep parameters and daytime function.

\section{Disclosure}

The author reports no conflicts of interest in this communication.

\section{References}

1. Horne J. Is there a sleep debt? Sleep. 2004;27(6):1047-1049.

2. Dinges DF. Sleep debt and scientific evidence. Sleep. 2004;27(6): 1050-1052. 
3. Galambos NL, Vargas Lascano DI, Howard AL, Maggs JL. Who sleeps best? Longitudinal patterns and covariates of change in sleep quantity, quality, and timing across four university years. Behav Sleep Med. 2013;11(1): $8-22$.

4. Lund HG, Reider BD, Whiting AB, Prichard JR. Sleep patterns and predictors of disturbed sleep in a large population of college students. J Adolesc Health. 2010;46(2):124-132.

5. Eliasson AH, Lettieri CJ, Eliasson AH. Early to bed, early to rise! Sleep habits and academic performance in college students. Sleep Breath. 2010;14(1):71-75.

6. Rajaratnam SM, Middleton B, Stone BM, Arendt J, Dijk DJ. Melatonin advances the circadian timing of EEG sleep and directly facilitates sleep without altering its duration in extended sleep opportunities in humans. J Physiol. 2004;561(Pt 1):339-351.

7. Wolfson AR, Carskadon MA. Sleep schedules and daytime functioning in adolescents. Child Dev. 1998;69(4):875-887.

8. Consensus Conference Panel, Watson NF, Badr MS, et al. Joint Consensus Statement of the American Academy of Sleep Medicine and Sleep Research Society on the Recommended Amount of Sleep for a Healthy Adult: Methodology and Discussion. Sleep. 2015;38(8):1161-1183.
9. WehrTA, Moul DE, Barbato G, et al. Conservation of photoperiod-responsive mechanisms in humans. Am J Physiol. 1993;265(4 Pt 2):R846-R857.

10. Klerman EB, Dijk DJ. Interindividual variation in sleep duration and its association with sleep debt in young adults. Sleep. 2005;28(10):1253-1259.

11. Kryger MH, Roth T, Dement WC, editors. Principles and Practice of Sleep Medicine. St. Louis: Elsevier; 2005.

12. Amlander CJ, Fuller PM, editors. Basics of Sleep Guide, Second Edition. Westchester, Illinois: Sleep Research Society; 2009.

13. American College Health Association. National College Health Assessment: Fall 2015 Reference Group Data Report. American College Health Association; 2015. Available from: http://www.acha-ncha.org/ docs/NCHA-II\%20FALL\%202015\%20REFERENCE\%20GROUP\%20 EXECUTIVE\%20SUMMARY.pdf. Accessed April 1, 2016.

14. O'Brien MC, McCoy TP, Rhodes SD, Wagoner A, Wolfson M. Caffeinated cocktails: energy drink consumption, high-risk drinking, and alcohol-related consequences among college students. Acad Emerg Med. 2008;15(5):453-460.

15. Velazquez CE, Poulos NS, Latimer LA, Pasch KE. Associations between energy drink consumption and alcohol use behaviors among college students. Drug Alcohol Depend. 2012;123(1-3):167-172.

Dove Medical Press encourages responsible, free and frank academic debate. The content of the Nature and Science of Sleep 'letters to the editor' section does not necessarily represent the views of Dove Medical Press, its officers, agents, employees, related entities or the Nature and Science of Sleep editors. While all reasonable steps have been taken to confirm the content of each letter, Dove Medical Press accepts no liability in respect of the content of any letter, nor is it responsible for the content and accuracy of any letter to the editor.

\section{Publish your work in this journal}

Nature and Science of Sleep is an international, peer-reviewed, open access journal covering all aspects of sleep science and sleep medicine, including the neurophysiology and functions of sleep, the genetics of sleep, sleep and society, biological rhythms, dreaming, sleep disorders and therapy, and strategies to optimize healthy sleep. The manuscript
Dovepress

management system is completely online and includes a very quick and fair peer-review system, which is all easy to use. Visit http://www. dovepress.com/testimonials.php to read real quotes from published authors. 